\title{
Desafios colocados pelas estratégias neoliberais de precarização do trabalho para a pesquisa-intervenção voltada para a transformação das situações de trabalho
}

\author{
Hélder Pordeus Muniz, ${ }^{\mathrm{I},}$, Emerson Moraes Teixeira ${ }^{\mathrm{II}, 2}$ e \\ Cláudia Osório da Silva ${ }^{\text {III, } 3}$ \\ ${ }^{\mathrm{I}}$ Universidade Federal Fluminense (Niterói, RJ, Brasil) \\ ${ }^{\text {II }}$ Fundação Jorge Duprat Figueiredo de Segurança e Medicina do Trabalho \\ (Rio de Janeiro, RJ, Brasil) \\ III Universidade Federal Fluminense (Niterói, RJ, Brasil)
}

\begin{abstract}
Este artigo apresenta os referenciais teóricos e metodológicos que dão suporte a nossos trabalhos e combates acadêmicos em face das estratégias neoliberais, sendo aqueles articulados a uma reflexão sobre pesquisa e intervenção em psicologia do trabalho. As políticas neoliberais adotadas na atualidade têm gerado efeitos importantes de precarização da vida e em especial nos meios de trabalho, resultando em alguns efeitos subjetivos perversos que se apresentam como desafios a serem enfrentados pelos trabalhadores na contínua invenção de sua vida e proteção de sua saúde. Discutimos como as ferramentas das clínicas do trabalho auxiliam a transformação das situações de vida e trabalho por meio da ampliação do poder de agir dos trabalhadores. Propomos, por fim, seguir nos debates do campo da psicologia do trabalho e organizacional no Brasil - sobre essas estratégias que visam transformar, e não apenas conhecer.
\end{abstract}

Palavras-chave: Neoliberalismo, Subjetivação, Cooperação, Cooperação conflitual.

Precarization of labor and neoliberal strategies posing challenges to intervention-research aiming to transform work situations

This article presents the theoretical and methodological references that support our studies, interventions and academic combats in work psychology in the face of neoliberal strategies articulated with reflections on research and intervention. The neoliberal policies adopted today have generated important effects of precariousness in life, and specifically in the work environment, generating some perverse subjective effects that function as challenges to be faced by workers in the continuous invention of their life and protection of their health. We discuss how the tools of work clinics assist in transforming life and work situations by expanding the workers' power to act. We propose to continue in debates in the field of work and organizational psychology in Brazil—strategies that aim to transform, and not just know.

Keywords: Neoliberalism, Subjectivation, Cooperation, Conflictive cooperation.

\section{Introdução}

$\mathrm{E}$ ste ensaio visa apresentar os referenciais epistemológicos, teóricos e metodológicos que dão suporte aos nossos trabalhos e aos combates acadêmicos para enfrentar problemas criados pelas estratégias neoliberais e de precarização da vida, articulados a uma reflexão sobre a nossa política de pesquisa e intervenção em psicologia do trabalho.

Primeiramente, apresentaremos algumas características das transformações induzidas pelas políticas neoliberais e de precarização da vida nos mundos do trabalho. Em um segundo tópico, levantaremos alguns efeitos subjetivos perversos que se comportam como desafios a serem enfrentados pelos trabalhadores na contínua invenção de sua vida e proteção de sua saúde. No terceiro tópico, mostraremos as perspectivas epistemológicas e abordagens teórico-metodológicas

\footnotetext{
https://orcid.org/0000-0001-8430-3647

https://orcid.org/0000-0002-5643-5877

https://orcid.org/0000-0001-8581-7842
} 
que fundamentam nossas pesquisas-intervenções, visando à ampliação do poder de agir dos trabalhadores. Não traremos aqui as pesquisas e intervenções que podem ser encontradas em outras publicações (Conceição, Rosa \& Santorum, 2018; Osório da Silva \& Barros de Barros, 2013; Alves \& Osorio da Silva, 2014; Neves, Muniz, Alvarez, Figueiredo \& França, 2018; Neves, Muniz, Silva, Brito \& Athayde, 2015).

Por fim, faremos, nas considerações finais, o nosso posicionamento em face dos debates do campo da psicologia do trabalho e organizacional no Brasil.

\section{Estratégias neoliberais e de precarização da vida e do trabalho}

Ideias neoliberais defendem a não participação do Estado na economia. Afirmam que deve haver total liberdade de comércio para garantir o crescimento econômico, o desenvolvimento social de um país e um estado natural da sociedade. O livre mercado seria o regulador natural da sociedade. Para essa ontologia naturalista, permitir que esse estado natural flua por si próprio significaria o equilíbrio, a estabilidade. A intervenção do governo nesse curso espontâneo prejudicaria o crescimento - espera-se dele a abstenção. Embora enfrentando crises diversas, as investidas neoliberais, ao longo dos anos, não arrefecem.

De acordo com Dardot e Laval (2016), aqueles que anunciam o fim do neoliberalismo incorrem em grande erro e apontam para a confusão feita entre as ideias econômicas que sustentam a implantação das políticas neoliberais e a normatividade prática que caracteriza o neoliberalismo propriamente. Os autores apresentam um questionamento: "como é que, apesar das consequências catastróficas a que nos conduziram as políticas neoliberais, essas políticas são cada vez mais ativas, a ponto de afundar os Estados e as sociedades em crises políticas e retrocessos sociais cada vez mais graves?" (Dardot \& Laval, 2016, p. 15). A resposta não estaria restrita, por exemplo, ao desmonte das regras, regulamentações e organizações do Estado. O neoliberalismo não tem apenas efeitos destrutivos, ele também produz determinadas relações sociais, certos modos de viver - modifica os modos como somos levados a nos comportar e a nos relacionar com o mundo e com nós mesmos.

Antes mesmo de pensar o neoliberalismo como ideologia ou política econômica, é fundamental ressaltar que ele é uma racionalidade.

O termo racionalidade não é empregado aqui como um eufemismo que nos permite evitar a palavra "capitalismo". O neoliberalismo é a razão do capitalismo contemporâneo, de um capitalismo desimpedido de suas referências arcaizantes e plenamente assumido como construção histórica e norma geral de vida. O neoliberalismo pode ser definido como o conjunto de discursos, práticas e dispositivos que determinam um novo modo de governo dos homens segundo o princípio universal da concorrência (Dardot \& Laval, 2016, p. 17).

Há uma produção constante de normas de vida dirigidas às sociedades ocidentais e àquelas que perseguem viver no caminho da chamada modernidade. Essas normas introduzem em nossas relações e práticas cotidianas a competição generalizada, que consiste na luta econômica, uns contra os outros, conforme o modelo do mercado - em que o indivíduo passa a se conceber e se comportar como uma empresa. Nas teias neoliberais, a "norma de vida rege as políticas públicas, comanda as relações econômicas mundiais, transforma a sociedade" e dá novos contornos aos modos de viver (Dardot \& Laval, 2016, p. 16).

Vemos os efeitos dessas normas nas relações sociais individualizantes, na polarização aguda entre pobres e ricos e no surgimento de novos sujeitos. Para impor suas normas, o neoliberalismo age, também, na direção do enfraquecimento dos entes do Estado e nos direitos que os trabalhadores 
conquistaram a duras penas por meio de suas lutas históricas. Nesses termos, "tende a estruturar e organizar não apenas a ação dos governantes, mas até a própria conduta dos governados" (Dardot \& Laval, 2016, p. 17). A característica principal da racionalidade neoliberal é a concorrência generalizada como norma condutora e a empresa como modelo de subjetivação.

Nas últimas quatro décadas houve a transformação do capitalismo em dimensão mundial. Sob a regência da acumulação flexível ${ }^{4}$ se deu a ruptura com os padrões fordistas, "gerando um modo de trabalho e de vida pautados na flexibilização e na precarização do trabalho" (Antunes, 2018, p. 153). Os empreendimentos do capital passaram a ser dirigidos pelo capital financeiro, que, por sua vez, subordinou a esfera produtiva afetando as práticas e os modos de gestão do trabalho. Segundo Antunes (2018), o Estado passou a desempenhar cada vez mais um papel de gestor dos negócios da burguesia financeira, cujos governos, em sua imensa maioria, pautam-se pela desregulamentação dos mercados, principalmente o financeiro e o de trabalho. Estamos diante da experiência de hegemonia da lógica financeira que alcança não somente a esfera econômica, mas também a da vida social, modificando os modos de trabalho e de vida, tornando os trabalhadores vulneráveis, efêmeros e descartáveis.

É a lógica do curto prazo, que incentiva a "permanente inovação" no campo da tecnologia, dos novos produtos financeiros e da força de trabalho, tornando obsoletos e descartáveis os homens e mulheres que trabalham. São tempos de desemprego estrutural, de trabalhadores e trabalhadoras empregáveis no curto prazo, por meio das (novas e) precárias formas de contrato, em que terceirização, informalidade, precarização, materialidade e imaterialidade são mecanismos vitais, tanto para a preservação quanto para a ampliação da sua lógica (Antunes, 2018, pp. 153-154).

Entre as dimensões e modalidades de precarização do trabalho no Brasil, Franco e Druck (2008) apontam a terceirização como fenômeno central. Nela, encontramos contratações precárias, sem proteção social e com salários mais baixos. Os terceirizados são os que mais se acidentam e morrem no trabalho dadas as condições precárias para a realização do seu trabalho.

Sobre "os padrões de gestão e organização do trabalho", inspirados no toyotismo ${ }^{5}$, revelam-se condições extremamente precárias, com a intensificação do trabalho (imposição de metas inalcançáveis, extensão da jornada, polivalência etc.) sustentada na gestão pelo medo, nas formas de abuso de poder, no assédio moral e na discriminação criada pela terceirização. É entre os terceirizados que essas condições de trabalho são piores, com maiores jornadas, maior rotatividade e menor acesso a benefícios (Antunes, 2018, pp. 158-159).

As evidências no mundo do trabalho nos convocam a refletir acerca das condições dadas aos trabalhadores para que realizem seu trabalho. Perante tantas investidas e lógicas perversas de fomento

4 Após a recessão, em 1973, inicia-se a transição do processo de acumulação de capital (Antunes, 1995, p. 20). A acumulação flexível nos diz que essa fase da produção é "marcada por um confronto direto com a rigidez do fordismo. Ela se apoia na flexibilidade dos processos de trabalho, dos mercados de trabalho, dos produtos e padrões de consumo. Caracteriza-se pelo surgimento de setores de produção inteiramente novos, novas maneiras de fornecimento de serviços financeiros, novos mercados e, sobretudo, taxas altamente intensificadas de inovação comercial, tecnológica e organizacional. A acumulação flexível envolve rápidas mudanças dos padrões do desenvolvimento desigual, tanto entre setores como entre regiões geográficas, criando, por exemplo, um vasto movimento no emprego no chamado "setor de serviços", bem como conjuntos industriais completamente novos em regiões até então subdesenvolvidas ..." (Harvey, 1992, p. 140).

5 Nas transformações do capitalismo vivencia-se a mudança dos processos de trabalho com a chegada do toyotismo, cunhado na flexibilização da produção, em lugar dos paradigmas tayloristas e fordistas baseados na produção em série e de massa, no controle do tempo e movimentos. "O toyotismo penetra, mescla-se ou mesmo substitui o padrão fordista dominante, em várias partes do capitalismo globalizado. Vivem-se formas transitórias de produção, cujos desdobramentos são também agudos, no que diz respeito aos direitos do trabalho. Estes são desregulamentados, são flexibilizados ... Direitos e conquistas históricas dos trabalhadores são substituídos e eliminados do mundo da produção" (Antunes, 1995, pp. 20-21). 
do capital, somos desafiados a interrogar as práticas e o sentido do trabalho - além de ponderar sobre outros modos de ser e fazer no trabalho -, a reconhecer a complexidade do 'ser no mundo' sob a égide dos paradigmas neoliberais, a trilhar um caminho e a construir nesse caminhar, sendo impulsionados pela postura ética com a vida.

\section{Efeitos subjetivos do neoliberalismo e da precarização}

Um dos principais efeitos subjetivos do neoliberalismo e da precarização é a produção de insegurança e de medo de reivindicar e lutar, devido à dificuldade de conseguir manter um emprego. Além disso, a diferenciação de contratos entre os trabalhadores de uma mesma empresa, como entre os terceirizados e os diretamente contratados pela empresa principal, produz conflitos entre os trabalhadores, que não estão submetidos às mesmas regras jurídicas e nem possuem os mesmos direitos. Muitas vezes, eles não têm o mesmo sindicato ou associação para reuni-los em uma luta comum ${ }^{6}$.

As contribuições das pesquisas nas diferentes clínicas do trabalho (Bendassolli \& Soboll, 2011; Lhuilier, 2006) têm salientado a importância da dimensão coletiva do trabalho, que se expressa na cooperação entre trabalhadores para produzirem saberes e normas a partir de valores do bem comum que confrontam os valores mercantis (Schwartz, 2010a). Essa cooperação exige uma construção árdua que depende de uma história do ofício, das relações laborais e do modo como os trabalhadores lutam pela qualidade de seu fazer e pela sua saúde.

Assim, outro efeito perigoso da precariedade dos contratos de trabalho é a fragmentação dos coletivos, uma vez que o fato produz uma grande rotatividade de trabalhadores, fazendo com que os acordos coletivos que começavam a se consolidar sejam destruídos e os trabalhadores necessitem construí-los novamente. Isso fragiliza as relações de confiança porque, enquanto acordos não são firmados coletivamente e não se cria o hábito de cumpri-los no cotidiano de trabalho, não existe a confiança de que será possível trabalhar com cuidado - não só pela qualidade do trabalho, mas também pela saúde das pessoas. Nas relações cotidianas de trabalho, produz-se uma permanente sobrecarga, uma vez que, na ausência da certeza de que normas coletivas referenciarão o trabalho, resta aos trabalhadores tomarem para si a responsabilidade pessoal de gerir o seu trabalho e de vigiar o do outro, em uma situação na qual seria necessário um suporte coletivo. Isso leva à personalização dos conflitos, causando atritos, críticas pessoais e moralização das atitudes, como se a única referência restante fosse o conjunto de normas morais e universais a priori, que devessem ser seguidas sem um retrabalho necessário de sua pertinência no contexto de cada atividade.

Dejours (2012) refere-se também a situações nas quais a gerência tenta construir a cooperação por meio da produção do medo. Os trabalhadores são convocados a cooperar com a gerência devido à ameaça da demissão ou punição, não existindo espaço para um debate sobre as normas entre elas, as prescrições. Dessa forma, as pessoas procuram uma cooperação reduzida em busca das compatibilidades: os trabalhadores procuram ajustar seu modo operatório para que seja compatível com outra instância humana ou objeto técnico. Ou seja, há um esforço de cada um de procurar um nível de comunicação com colegas e chefias que permita a continuidade das tarefas. Porém, muitos dos problemas que aparecem e dificultam o trabalho não são informados e discutidos porque isso seria assumir que as normas não podem ser sempre cumpridas ou que o seu cumprimento produz problemas. Essa questão pode ser encarada pela gerência como um defeito do trabalhador, que não soube ser criativo e lidar com os incidentes respeitando as normas existentes.

6 Dizemos isso sem ignorar que essa forma de luta está em busca de formas de enfrentamento que levem em conta os novos desafios apresentados pelo neoliberalismo atual. 
Nesse modo de relação vai decaindo o esforço de cooperação e se acentua o isolamento, a ênfase na estratégia de fazer o máximo de coisas sozinho, sem depender dos outros. As relações de cooperação diminuem o máximo possível e a comunicação passa a ser feita predominantemente por mensagens via e-mail ou outro tipo de comunicação simplificada. A própria forma como essas mensagens vão ser efetuadas é um indicador da degradação dos coletivos de trabalho, dado que sempre se procura responder a um número grande de pessoas de forma a ficar público e provado que cumpriu a sua parte. Assim, caso ocorra algum problema, o trabalhador não será facilmente atingido pela culpabilização, tão presente nesse tipo de gerência pelo medo.

Trata-se da ilusão de que, se cada um fizer a sua parte, tudo correrá bem. Porém, os estudos sobre a atividade humana em situação de trabalho já mostraram que a variabilidade técnica e humana exige regulação e produção de novas normas para trabalhar, essas não podendo ser reduzidas a decisões individuais. Assim, embora esse tipo de cooperação possibilite algum tipo de coordenação das tarefas, ele não dá conta de variabilidades que exigem uma gestão coletiva complexa da situação ela envolve uma atividade deôntica de produção de acordos para referenciar as regulações. Dessa forma, problemas surgirão tanto na qualidade da produção quanto na saúde dos trabalhadores, áreas em que o coletivo some e o trabalhador também se degrada:

Na cooperação reduzida em busca de compatibilidades, a cooperação se faz exclusivamente com os objetos técnicos, enquanto as relações humanas se empobrecem e se tornam rarefeitas. Nessa cooperação sob o regime do medo, a convivência não pode resistir e os espaços informais desaparecem. A patologia da solidão e desolação rondam, o que significa, de forma concreta, que em caso de ruptura, de grande dificuldade, de "naufrágio", o sujeito que malogra não pode contar com ninguém (Dejours, 2012, p. 91).

Tal efeito piora mais ainda com a crescente utilização de formas de avaliação de desempenho individuais, e essas formas produzem concorrências muitas vezes desleais entre trabalhadores, destruindo solidariedades.

Dardot e Laval (2016) afirmam que o neoliberalismo introduz um modo de viver baseado no empreendedorismo, em que cada trabalhador compete com os outros para vencer na vida. Esse enfraquecimento dos coletivos diminui a capacidade de luta dos movimentos - seja por aumento salarial, seja pela melhoria das condições e da organização do trabalho. A ruptura da luta coletiva, substituída pelas tentativas individuais de se diferenciar dos demais para ganhar benefícios ou se proteger de punições ou demissões, vai piorando ainda mais as situações de precarização, já que uma crítica ativa coletiva não é exercida.

Porém, além de apresentar esses efeitos deletérios na vida dos trabalhadores, precisamos atentar às possibilidades de enfrentamento da atual organização empresarial do trabalho neoliberal e de como a nossa prática em psicologia do trabalho pode contribuir para ampliar o poder de agir dos trabalhadores. Como diz Clot (2010, p. 15), o desenvolvimento do poder de agir relaciona-se com o "raio de ação efetivo do sujeito em sua esfera profissional, o que se pode também designar por irradiação da atividade, seu poder de recriação".

As diferentes clínicas do trabalho têm em comum a valorização do coletivo e o debate sobre o trabalho em situação concreta como o caminho - o método - por excelência, de permanente construção de recursos coletivos para a ação - ou, pode-se dizer, para uma efetiva cooperação.

O trabalho tem sentido e eficiência quando os trabalhadores dispõem de recursos para a ação que lhes permitem reconhecer-se em um trabalho que considerem bem-feito e, em diálogo com os valores de ofício, dele se orgulhem. Alcançar sentido e eficiência exige manter e permanentemente construir uma cooperação conflitual, considerando uma dada organização do trabalho. Assim, 
... é nesse sentido que buscamos avançar até o ponto de colisão dos conflitos de critérios de qualidade do trabalho, levando conosco os profissionais, tendo em vista sustentar os esforços necessários à instituição de uma cooperação conflitual dentro da organização do trabalho (Simonet \& Poussin, 2014).

Intervir no desenvolvimento da atividade para aumentar o poder de agir é então oferecer aos que trabalham - sejam operadores, gerentes ou diretores com maior poder de decisão - o enriquecimento do conflito entre sentido e eficiência, com o objetivo da eficácia. Em nome da saúde, que é uma preocupação atual dos que solicitam nossa intervenção, assim como é a nossa própria preocupação, parece indispensável ocupar-se da eficácia do trabalho. ... A eficácia contrariada é uma fonte importante de atentado à saúde (Clot \& Simonet, 2015, p. 45).

É necessário sustentar uma cooperação que não procure esconder os conflitos de critérios que ocorrem no diálogo difícil com a organização do trabalho: instituir uma cooperação conflitual. Uma cooperação efetiva exige o enfrentamento do debate da qualidade do trabalho e dos critérios de trabalho bem-feitos, em que os trabalhadores participem ativamente, sem falsas concordâncias escondendo a heterogeneidade de interesses envolvidos.

\section{Como a psicologia do trabalho pode apoiar a luta contra os efeitos do neoliberalismo e da precarização do trabalho?}

Em nossas práticas de pesquisa-intervenção, utilizamos uma caixa de ferramentas com diferentes teorias, diferentes disciplinas do conhecimento e, ao mesmo tempo, com a mobilização dos saberes dos trabalhadores que são construídos nas suas práticas de luta pela vida e pela emancipação política. Esses patrimônios de conceitos teóricos e cotidianos são colocados em debate buscando o desenvolvimento dos saberes científicos e saberes da experiência.

Neste artigo, exploraremos a contribuição da ergologia e da clínica da atividade para a ampliação da capacidade de intervenção dos trabalhadores em suas situações de trabalho.

\section{Ergologia e a atividade humana como debate de normas em um mundo de valores}

Schwartz (2010b) adverte que devemos ter humildade epistemológica na avaliação das mudanças nas situações de trabalho. Ele afirma que é necessário o estudo das atividades humanas em situação de trabalho para apreender como os trabalhadores experienciam essas mudanças, partindo do pressuposto de que eles não são meros fantoches, manipulados e programados para se comportarem conforme as políticas de gerenciamento prescrevem. Isso implica que não podemos prescindir do protagonismo dos trabalhadores na análise das situações de trabalho, em confronto e diálogo com os pesquisadores/analistas do trabalho.

A partir de Canguilhem (2011), compreendemos que a vida é atividade em oposição à inércia e à indiferença. Schwartz (2015) elabora então a concepção de que a atividade envolve sempre um debate de normas. As normas antecedentes que referenciam a atividade humana estão sempre em movimento de renormatização, pelo qual os trabalhadores procuram criar um meio de vida e trabalho mais coerente com os valores que querem afirmar. Não significa dizer que há sempre sucesso nessa renormatização ou que os trabalhadores consigam, com certeza, reconstruir um meio favorável de trabalho e de vida. Porém, convém reforçar que mesmo as tentativas malsucedidas, os fracassos parciais, sugerem não apenas a existência da passividade e da reatividade como possibilidade de atitude dos trabalhadores. 
Assim, Schwartz (2014) propõe que o trabalho exige sempre uso de si por outros (heterodeterminação por normas históricas e sociais) e também uso de si por si (criação de novas normas por parte dos trabalhadores). Esse "si" não é sinônimo de um eu essencializado ou de um indivíduo a-histórico - Schwartz (2014) deixa mais clara sua concepção quando propõe que se trata de um corpo-si, uma entidade que é um encontro ou atravessamento de três histórias: a história dos seres vivos e, portanto, das mudanças nas normas vitais; a história social, fazendo com que a atividade humana seja sempre atravessada por normas sociais; e, por fim, a história singular de cada trabalhador desde o seu nascimento até a sua morte, desenvolvendo uma experiência concreta de vida, irrepetível e singular.

Desse modo, ao propor o trabalho como uso do corpo-si, o autor busca romper com as dicotomias: vida/história; indivíduo/sociedade e corpo/mente. Não há nunca atividade meramente individual, nem um amálgama social que iguala as experiências de todos os trabalhadores. Não é possível entender a atividade de cada trabalhador sem compreender os processos histórico, social, econômico e político global dos quais faz parte e, ao mesmo tempo, não se entende a sociedade sem compreender que os coletivos são construídos à base de debates, visto que as atividades não são meros reflexos de uma norma homogênea seguida por todos (Muniz, Santorum \& França, 2008).

Outra concepção importante desse autor é a de entidades coletivas relativamente pertinentes (Schwartz, 2010c), formulada para ressaltar que a produção de novas normas em situações de trabalho envolve a construção coletiva. Os trabalhadores precisam construir comunicações e colaborações entre suas atividades, formando uma intervenção coletiva provisória no trabalho que ultrapassa os limites do organograma e recria normas. Essas articulações coletivas são relativamente pertinentes porque suas fronteiras são as da atividade situada de trabalho, e só se compreende sua pertinência naquela dimensão temporal e naquela amplitude de análise que se quer realizar. Essas entidades coletivas relativamente pertinentes oferecem um lugar de transição entre o político e o trabalho. Se essas entidades coletivas relativamente pertinentes se constroem, isso quer dizer que os valores entre as pessoas são bastante fortes para as cristalizarem - tais valores aderem à própria atividade e são, portanto, pregnantes para as pessoas que estão no local (Schwartz, 2010c, p. 163).

Schwartz (2016) salienta que a atividade processa um debate de normas em um mundo de valores. As normas são a dimensão mais operacional e revelam, muitas vezes, um embate que requer uma decisão entre posições antagônicas. Por exemplo: uma enfermeira deve decidir se é aconselhável, em uma situação específica, acordar ou não um paciente para que ele tome um remédio. Um motorista de ônibus é confrontado com a decisão de parar fora dos pontos formalmente estabelecidos para que um passageiro desça no lugar mais conveniente para ele ou respeitar fielmente a prescrição.

Todas essas decisões não são neutras, já que se baseiam em valores. Na vida social, encontramos os valores mercantis, que são dimensionados quantitativamente - por exemplo, o quanto de dinheiro se economiza ou se gasta na quantidade de paradas dos ônibus. Além disso, existem também valores do bem comum, que não estão dimensionados inicialmente (como justiça, saúde, educação e autonomia). Esses valores, para ganhar uma concretude na vida social, precisam ser dimensionados por meio da produção de normas, e essa é uma das grandes questões da gestão do trabalho, pois não é óbvio como um valor como a saúde pode se tornar operacional (Schwartz, 2016). Além disso, uma mesma norma pode estar relacionada com diferentes valores - para dar apenas um exemplo: um médico, ao decidir dar alta a um paciente, pode afirmar um valor associado a um bom tratamento como saúde ou autonomia, mas também a um valor mercantil, de redução de custos no serviço de saúde pública que precisa ampliar a rotatividade de pacientes para compensar gastos.

É fundamental haver uma discussão das normas em suas relações com os valores no trabalho, para os trabalhadores construírem coletivamente modos de trabalhar e conviver juntos no trabalho 
que estejam articulados a determinadas concepções de vida social. É dessa forma que o autor salienta a relação entre políticas de gestão do trabalho com um projeto de construção social mais amplo.

A ideia de trabalhar juntos na definição de bens comuns, na sua gestão e cristalização em instituições, regras, normas têm uma pertinência, uma significação. É a razão pela qual eu digo que, de certa maneira, o político (o político ou o econômico, no sentido amplo) determina a natureza, a possibilidade, a configuração dessas entidades pertinentes. Mas, inversamente, podemos dizer que ao mesmo tempo o político começa lá, no nível mais local.

Em outros termos, se o bem comum, se esses valores têm bastante aderência e força para organizar entidades pertinentes, isso quer dizer que a questão do viver junto e sua determinação têm um sentido e uma significação para as pessoas. Eu diria, de forma mais geral, que o político - como o lugar no qual se debate acerca do viver juntos e do bem comum - ganha então um sentido. Consequentemente, pode-se pensar em um certo grau de participação coerente dessas pessoas nos debates, no campo do político e dos valores relativamente universais que eu chamo de valores sem dimensão (Schwartz, 2010c, p. 164).

Schwartz (2010c) também faz um alerta: se ocorre o processo contrário, tão presente nas políticas de gerenciamento neoliberais, a ponto de estimular a individualização, a concorrência e a destruição de coletivos, é provável que se produza um sentimento de desgosto generalizado pelo político, dado que o ato político é constantemente vivenciado como um maltrato.

É fundamental a análise de como se processa a dimensão coletiva do trabalho: quais os obstáculos para a cooperação e como os trabalhadores lutam para trabalhar, apesar de tudo? Em nossas pesquisas, além de estarmos atentos aos problemas relativos à saúde dos trabalhadores e à qualidade do trabalho, procuramos também inverter a questão e nos perguntarmos: como algo ainda funciona, apesar de tudo? Essa questão visa abordar como se processam as entidades coletivas relativamente pertinentes e as atividades humanas no esforço de construção e reconstrução de normas para afirmar valores de uma vida em comum. Não fazemos isso para amenizar ou eufemizar a percepção da dura realidade da precarização, mas porque acreditamos que a transformação só é possível quando detectarmos as mínimas potencialidades presentes de construção coletiva de exercício de novas formas de viver juntos.

A melhor forma de lidar com a precarização é não deixar que ela contamine o nosso olhar a ponto de não enxergarmos as possíveis potências de transformação e de luta presentes nas situações de vida e trabalho. Nesse sentido, o conceito de atividade nos é precioso, porque nos leva à frente das situações de trabalho, em que os trabalhadores se arriscam tomando decisões, vivenciando debates de normas, arbitrando entre normas, antecedentes e renormatizações. Nesse movimento, entidades coletivas são construídas, destruídas e reconstruídas. Não devemos nem superestimar, nem subestimar as possibilidades de construção coletiva. Quando se observa um processo querendo compará-lo com o que acontecia anos atrás, a tendência é achar que a dominação sobre os trabalhadores é completa, que não há mais coletivo ou luta, porque não enxergamos hoje as mesmas expressões e formas de coletivo que existiam antes. Nesse sentido, centrar o olhar apenas nas consequências negativas do novo capitalismo pode nos impedir de ver emergir outros processos de vida, outras experimentações e reservas de alternativas presentes na atividade (Schwartz, 2015).

Pensamos que a luta contra a desigualdade e a injustiça social também acontece na linha de frente das situações de trabalho. Retomamos as contribuições de Oddone, Re e Briante (1981), que afirmam que os trabalhadores vivem uma experiência de luta cotidiana em suas situações de trabalho e que produzem saberes fundamentais que servem tanto para fazer o seu trabalho como para construir uma experiência de classe comum. Isso não quer dizer que não ocorram equívocos e derrotas parciais nessas tentativas de assumir minimamente o controle de suas vidas, apesar 
da organização empresarial do trabalho produzir sérios obstáculos à construção autônoma dos trabalhadores. O que se propõe é criar oportunidades de reflexão coletiva sobre as experiências para poder desenvolvê-las, aumentando assim o poder de agir dos trabalhadores. Ao assumirem a tarefa de discutir e desenvolver coletivamente suas estratégias de trabalho e de luta, os trabalhadores fortalecem as formas de cooperação e criam novas estratégias de intervenção.

Dessa forma, se as políticas neoliberais produzem isolamento, fragmentação dos coletivos e desencontros, e também afirmam como valor a capacidade de vencer sozinho na vida, de empreender negócios e de ampliar capital para poder consumir mais do que os outros como ideal de vida, nossas estratégias de intervenção vão na sua contramão - ou seja, buscam a coletivização, o encontro e afirmam a solidariedade, além da construção coletiva na busca de afirmar valores do bem comum, como saúde, educação e autonomia para todos. Isso é possível na medida em que acreditamos, com Canguilhem (2001), que a normatividade não é um privilégio do capital. Não se trata de acreditar que é possível afirmar plenamente esses valores no capitalismo, mas de apostar na possibilidade de lutar por eles desde já, porque só assim será possível uma alternativa revolucionária a esta sociedade burguesa, que abandona seus valores democráticos sempre que é mais vantajoso economicamente flertar com o fascismo em nome da ampliação do capital - tudo isso por meio da exploração abusiva da força de trabalho, como acontece agora no Brasil. Trata-se de fortalecer a luta, e não de acreditar em um reformismo que visa dar uma aparência tolerável ao que é intolerável, guiando a prática política mediante o discurso de que o possível é fazer apenas pequenas melhorias nas situações de trabalho. A maior aposta é no fortalecimento da capacidade de luta dos coletivos de trabalhadores.

O dispositivo dinâmico de três polos e as comunidades ampliadas de pesquisa e intervenção: desenvolvimentos da ergologia no Brasil

Oddone, Re e Briant (1981) propuseram que a "comunidade científica ampliada" fosse um novo paradigma de produção de conhecimento sobre o trabalho, no qual os operários protagonizariam a produção do conhecimento junto a pesquisadores de diferentes disciplinas. Trabalhando com o movimento sindical italiano, os autores desenvolveram uma metodologia de formação de trabalhadores para a luta pela saúde no cotidiano das fábricas.

Schwartz (2000) salienta a relevância do conceito de "comunidade científica ampliada". Ele acredita, porém, que as transformações ocorridas no mundo do trabalho desde a década de 1970 criaram novos desafios para os pesquisadores e trabalhadores, como:

- interrogar-se sobre o papel da atividade na história da espécie humana, produzindo incessantemente novas normas e meios de vida e trabalho;

- esclarecer o trabalho de reavaliação de seus próprios saberes e práticas a ser realizado por pesquisadores e trabalhadores, respectivamente;

- ampliar os interlocutores, ou seja: além dos trabalhadores assalariados e sindicalistas, outros parceiros devem participar da produção de conhecimento sobre o trabalho, como desempregados, camelôs, terceirizados, gerentes do setor público ou privado, sem-terra, trabalhadores sem-teto e outros atores presentes no cenário atual.

Assim, Schwartz e Durrive (2016) apresentam o "dispositivo dinâmico de três polos (DD3P)" como uma nova formulação ética e epistemológica, que acrescenta outros conceitos e estratégias para pesquisar e intervir nas situações de trabalho no contexto do capitalismo contemporâneo. O polo 1 é o dos saberes disponíveis, "desinvestidos" (sobre o trabalho e muitas outras coisas), produzidos em diversos graus de desaderência. Nele se encontram as diferentes disciplinas acadêmicas em uma relação de pluridisciplinaridade, ou seja, em busca de um trabalho que 
afrouxe as fronteiras das disciplinas permitindo transversalizar os debates e impedir hierarquizações e desqualificações entre elas.

O polo 2 é o das forças de convocação, de reconvocação e de saberes investidos, tendencialmente produzidos em diversos graus de aderência. Essas forças convocam os saberes do polo 1 para contribuir com a compreensão-transformação da atividade, e, no processo, apresentam uma crítica a eles, os obrigando a serem retrabalhados; daí a ideia de reconvocação e transformação desses saberes acadêmicos, estimulando a criação de novos conceitos e teorias. Os saberes investidos na atividade - ou saberes da experiência - apresentam uma pertinência para a compreensão dos problemas, mas também se colocam em retrabalho no confronto com os saberes do polo 1 .

O polo 3 é o polo-suporte, polo dos desconfortos intelectuais, éticos, sociais - ou polo do mundo comum a ser construído. Trata-se de como arbitrar o encontro dos saberes do polo 1 e do polo 2 para que a cooperação não seja apenas tecnocrática, burocrática ou superficial, mas sim uma confrontação que leve ao retrabalho de ambos os saberes com o intuito de trabalhar os valores necessários para dar um sentido à pesquisa-intervenção. É fundamental mobilizar debates sobre quais são os objetivos da transformação e que mundo se quer construir para vivermos juntos. Isso envolve uma exigência epistemológica, ou seja: todos os participantes, sejam eles pesquisadores profissionais ou trabalhadores, devem estar abertos a aprender uns com os outros, reconhecendo no outro alguém capaz de lhe ensinar algo. Envolve também uma exigência ética, de reconhecer o outro como ser de atividade, que produz suas próprias normas e que tem suas posições os valores com os quais se quer viver e quais normas seriam as mais adequadas para tornar concretos esses valores na vida em comum.

No Brasil, um grupo de pesquisadores referenciados na proposta da comunidade científica ampliada (Muniz, Brito, Athayde, Souza \& Lacomblez, 2013) e do dispositivo dinâmico de três polos criou e experimentou o dispositivo denominado Comunidade Ampliada de Pesquisa (CAP) (Brito \& Athayde, 2003; Brito, Athayde \& Neves, 2003), que anos depois foi renomeado para Comunidade ampliada de pesquisa e intervenção (Capi) (Athayde, Zambroni-de-Souza \& Brito, 2014). Esse dispositivo tem a influência também do patrimônio das experiências brasileiras em educação popular (Freire, 1987; Garcia, 1980) no que diz respeito à produção de pesquisas e de processos de formação que envolvem a colaboração de saberes acadêmicos e populares que visam à transformação da realidade por meio da mobilização política. A palavra "comunidade" tem um sentido, no Brasil, ampliado por uma tradição de dispositivos de educação popular. A ideia de usar a palavra "pesquisa" em vez de "científica" busca evitar tanto a confusão de que esta seria uma produção científica tradicional e positivista, quanto a de que o objetivo seria formar trabalhadores como cientistas profissionais.

\section{A clínica da atividade: protagonismo do trabalhador em diálogo com seu trabalho}

A clínica da atividade surgiu na França alguns anos mais tarde, tendo à frente Yves Clot e Daniel Faïta (2000), que participavam das atividades iniciais da ergologia no sul da França. Ela compartilha com esta perspectiva o ponto de vista da atividade como indispensável nas análises e intervenções no trabalho; tem também em comum o conceito de saúde canguilhemiano e a busca pela ampliação de recursos coletivos para a ação dos trabalhadores em seu meio. Assim, "a análise do trabalho visa inicialmente assessorar esses coletivos em seus esforços para redobrar seu poder de agir em seu meio" (Clot \& Faïta, 2000, p. 8). Desse modo, busca-se revitalizar o gênero de atividade profissional, a instância transpessoal do ofício (Clot, 2010). No entanto, enquanto a ergologia procura ser uma perspectiva ética e epistemológica que pode orientar diferentes abordagens, 
a clínica da atividade fornece um enfoque clínico às situações de trabalho, com ferramentas teóricas conceituais e metodológicas próprias para o desenvolvimento de uma psicologia do trabalho.

Com o objetivo de desenvolvimento do poder de agir dos profissionais sobre seu meio, ou seja, de ampliação dos recursos coletivos para a ação dos trabalhadores sobre seu meio de trabalho, a clínica da atividade dedica esforços à produção de metodologia e métodos que provocam o diálogo sobre o trabalho, bem como o diálogo com o objeto de trabalho. Esse propósito acompanha o que já vinha sendo afirmado por Ivar Oddone: que as transformações desejadas só são consistentes se elas se dão por iniciativa dos próprios trabalhadores, em que os trabalhadores sejam protagonistas da análise e das transformações (Osorio da Silva, 2014). Fabricar dispositivos de análise do trabalho pelos quais os trabalhadores possam ser os protagonistas constitui, então, o principal desafio metodológico.

Em face dos constrangimentos da organização do trabalho, especificamente no capitalismo neoliberal da atualidade, o trabalhador que dispõe de recursos coletivos, de um gênero de atividade profissional em sua plena vitalidade, não se adapta ao meio; ele cria um meio para viver. É preciso mais do que preservar o equilíbrio, mais do que ser normal. Aliando-se a Canguilhem (2011), a clínica da atividade afirma que, se a normalidade se define por adaptar-se a um meio e às suas exigências, a saúde se explica pela capacidade de seguir novas normas de vida.

Longe de ser um dado natural, a saúde é um poder de ação sobre si e sobre o mundo, adquirido junto dos outros. Ela está ligada à atividade vital de um sujeito, àquilo que ele consegue, ou não, mobilizar de sua atividade pessoal no universo das atividades do outro; e, inversamente, àquilo que ele chega, ou não, a utilizar das atividades do outro em seu próprio mundo (Clot, 2010, p. 111).

Propondo um diálogo em que intervêm Canguilhem e Vygotsky, Clot afirma que "a saúde, diferentemente da normalidade defensiva, é a transformação da doença em novo meio de existir, a metamorfose de uma experiência vivida em um meio de viver outras experiências ..." (Clot, 2010, p. 113).

Para fazer da experiência vivida um meio de viver novas experiências, a atividade é então tomada como objeto de análise em que os trabalhadores são necessariamente os protagonistas. Debater os detalhes da atividade realizada, trazendo à tona decisões tomadas por vezes em situações de grandes conflitos, em que se enfrentam dilemas e debates de escolas é o que faz da experiência já vivida um meio de viver novas experiências.

Ora, o exercício de uma clínica da atividade supõe a instalação proposital de um dispositivo desenvolvimental: a organização de uma nova atividade se superpõe à atividade ordinária que se busca transformar e compreender, ou melhor, transformar como indispensável para compreender.

Nessa metodologia, a pesquisa acerca do trabalho é sempre clínica, no sentido de que é situada e também de que deve produzir efeitos de desenvolvimento de recursos para a ação, sendo o trabalhador protagonista nessa coanálise. A intervenção se inicia, por isso, com uma fase de observação, para então o estabelecimento de um contrato de confiança entre o clínico e os trabalhadores.

A observação já produz, ela mesma, uma intervenção - entre outros motivos porque quem exerce a atividade profissional sob o olhar de outro tende a ficar perturbado, ao menos inicialmente, passando a se observar para ter algum controle sobre aquilo que o observador está vendo e pensando. Ora, na clínica da atividade, o efeito perturbador da observação é a fase inicial da análise da atividade em que o trabalhador é o principal analista. Aqui, a neutralidade não é um objetivo e o princípio se manterá na forma de fazer a análise da atividade, dado que ela será discutida e escolhida com o grupo que tem interesse em participar de modo direto do projeto, compondo um grupo de referência.

Complementarmente, outra referência fundamental para a clínica da atividade, inspirada na metodologia histórico-desenvolvimental proposta por Vygotsky, é a diferença entre comportamento realizado e desenvolvimento possível: 
Em 1925, ele já define o comportamento, distinguindo funcionamento realizado e desenvolvimento possível. O comportamento é um sistema de reações que foram vencedoras. Mas o realizado não é mais que uma ínfima parte daquilo que seria possível. O homem é pleno, a cada minuto, de possibilidades não realizadas. Assim, essas possibilidades suprimidas - que não são acessíveis diretamente, nem pelo sujeito nem por seu interlocutor - nem por isso deixam de agir (Clot, 2004, p. 7).

Daí a adoção de uma metodologia indireta que consiste em "transformar a experiência vivida de um objeto em objeto de nova experiência” (Vygotsky, 1925, citado por Clot, 2004, p. 7), e a análise incide sobre uma "marca" do trabalho, produzida coletivamente, como fruto do diálogo que põe o gênero de atividade profissional (Clot \& Faïta, 2000) em manutenção. Desse modo, criam-se condições para a produção de um distanciamento facilitador do debate sobre a atividade, evitando a personalização e o julgamento sobre escolhas pessoais. As polêmicas suscitadas são trazidas sem a consideração da necessidade de uma verdade ou de um objetivo de consenso. Ao contrário, a controvérsia é valorizada como um recurso para ampliação de recursos coletivos para a ação. O debate se faz de modo recorrente, favorecendo deslocamentos, elaborações e reelaborações nas análises produzidas. Uma mesma situação registrada é analisada sucessivamente, propiciando a participação, por meio do diálogo, de aspectos menos evidentes e conflitos da atividade.

Tendo como instrumento a análise do registro da atividade, desloca-se o trabalhador para o lugar de observador e analista do seu trabalho, mantendo-se o analista/pesquisador como instrumento do debate que se instala, confortando o mesmo deslocamento, convocando o trabalhador a expor, explicar suas ações e escolhas a alguém que não faz parte habitualmente da situação e não opera com as obviedades presentes para quem domina o ofício.

Esse modo de pesquisa-intervenção busca provocar, assim, as possibilidades que os trabalhadores têm de criar e recriar recursos para sua atividade profissional, levando-os à posição de observador de seu próprio trabalho - sendo o clínico um interlocutor visando possibilitar a surpresa com aquilo que, por muito familiar, já passava despercebido. A finalidade é então, claramente, favorecer o debate dos diferentes modos possíveis de enfrentamento do real, desenvolvendo o gênero do coletivo e ampliando suas possibilidades como instrumentos para a ação de cada um.

Dessa forma, o encontro com a clínica da atividade veio para enriquecer e criar outra sinergia no elenco das ferramentas metodológicas já adotadas no campo da saúde do trabalhador.

\section{Considerações finais}

O nosso trabalho tem produzido confrontos, colocando sob análise alguns debates que permeiam o campo da psicologia do trabalho no Brasil. Abre-se, assim, uma possibilidade interessante para pensar os rumos de pesquisa e intervenção que visam ampliar o poder de agir dos trabalhadores no contexto de gerenciamento neoliberal e de aumento da precarização do trabalho.

Na clínica da atividade, trabalha-se com a potência da controvérsia profissional como instrumento de ampliação dos recursos de gênero para ação, como fonte para a constituição de coletivos e como instrumento de desenvolvimento do pensamento. Acreditamos que contribui, também, para o desenvolvimento dos recursos teóricos metodológicos na área específica da psicologia do trabalho.

É recorrente o fato de psicólogos organizacionais verem clínicos do trabalho como alheios às necessidades da produção, às exigências de eficiência e eficácia - contrapondo-se ao paradigma apresentado no presente contributo. Outra controvérsia nos diz igualmente a respeito no âmbito da discussão colocada por uma crítica à clínica da atividade - e talvez também a outras clínicas do trabalho -, de que essa não pode pretender constituir uma resistência potente à dominação do trabalho pelo capital. Com esta perspectiva, Padilha (2009) afirma que, no cenário contemporâneo 
do trabalho, de alta exploração e dominação, qualquer proposta de transformação das condições de trabalho por intervenção direta nos ambientes organizacionais é, de fato, uma falácia, pelo entendimento de certos psicólogos influenciados por uma das interpretações possíveis do patrimônio marxista que associam tais modos de intervenção à negação da luta de classes, por contribuir a uma maior docilidade a serviço do capital.

A revista Trabalho, Educação e Saúde, periódico importante na área da saúde coletiva, optou por abrir este debate e, em face da postura de que só superando o capitalismo é que se pode alterar significativamente as relações de trabalho, outra posição (Athayde \& Brito, 2009; Lacaz, 2009) argumentou outro ponto de vista: as lutas importantes do presente são as que valorizam a ampliação da participação e o questionamento dos valores vigentes.

Percebemos a nossa responsabilidade de pesquisar as formas de gerenciamento e gestão do trabalho, com vistas a superar uma divisão feita no campo da psicologia do trabalho e organizacional entre os que supostamente seriam da saúde do trabalhador e os que estariam preocupados com a questão organizacional. É preciso afirmar uma prática que ouse intervir no mundo do trabalho tirando dos estudantes e psicólogos esta falsa escolha: entre ser um denunciador de esquerda fora das empresas ou estar dentro das empresas apenas para fazer um trabalho de aplicação de teorias e técnicas da moda. É preciso formar psicólogos do trabalho e organizacional que saibam problematizar as questões levantadas tanto pela gerência das empresas quanto pelos trabalhadores, além de analisar e reconstruir as demandas junto dos interlocutores - sem cair na cilada de limitar a formação dos alunos às demandas do mercado de trabalho. Isso porque o mercado não é natural, nem suas demandas - elas são construídas e transformadas. Para a universidade, não interessa se fixar apenas no que o mercado de trabalho é hoje, mas como ele poderá ser amanhã a partir das intervenções humanas.

Não acreditamos na fixação na suposta negatividade dos mundos do trabalho, nem no foco em uma suposta positividade. A vida no trabalho convoca trabalhadores e pesquisadores a assumirem riscos e escolhas difíceis, além de a avaliarem com quais movimentos se engajam. É uma aventura na qual ousamos lutar por valores do bem comum, enfrentando a hegemonia dos valores mercantis nos meios de vida e trabalho.

\section{Referências}

Alves, E. A. P. \& Osorio da Silva, C. (2014). Clínica da atividade e oficina de fotos: eletricistas em foco. Psicologia e Saúde, 6(2), 62-71.

Antunes, R. (2018). O privilégio da servidão: o novo proletariado de serviços na era digital. São Paulo: Boitempo.

Antunes, R. (1995). Adeus ao trabalho? Ensaios sobre as metamorfoses e a centralidade do mundo do trabalho. São Paulo: Cortez.

Athayde, M. \& Brito, J. (2009). Vida, saúde e trabalho: dialogando sobre a qualidade de vida no trabalho em um cenário de precarização. Trabalho, Educação e Saúde, 7(3), 587-597.

Athayde, M., Zambroni-de-Souza, P. \& Brito, J. C. (2014). Intervenção e pesquisa em psicologia: uma postura ergológica. In P. F. Bendassolli \& L. A. P. Soboll (Orgs.), Métodos de pesquisa e intervenção em psicologia do trabalho: clínicas do trabalho (pp. 129-157). São Paulo: Atlas.

Bendassolli, P. F. \& Soboll, L. A. P. (Orgs.). (2011). Clínicas do trabalho: novas perspectivas para a compreensão do trabalho na atualidade. São Paulo: Atlas.

Brito, J. \& Athayde, M. (2003). Trabalho, educação e saúde: o ponto de vista enigmático da atividade. Trabalho, Educação e Saúde, 1(2), 63-89.

Brito, J. C., Silva, E. F., Muniz, H., Neves, M. Y. \& Athayde, M. (Orgs.). (2003). Caderno de método e procedimentos: programa de formação em saúde, gênero e trabalho nas escolas. João Pessoa: Editora UFPB. 
Canguilhem, G. (2001). O meio e normas do homem no trabalho. Proposições, 12(2-3), 35-36.

Canguilhem, G. (2011). O normal e o patológico. Rio de Janeiro: Forense Universitária.

Clot, Y. (2004). Le travail entre fonctionnement et développement. Bulletin de Psychologie, 57 (1), 5-12.

Clot, Y. (2010). Trabalho e poder de agir. Belo Horizonte: Fabrefactum.

Clot, Y. \& Faïta, D. (2000). Genres et styles en analyse du travail. Concepts et méthodes. Travailler, 4, 7-42.

Clot, Y. \& Simonet, P. (2015). Pouvoir d'agir et marges de manouevre. Le Travail Humain, 78(1), 31-52.

Conceição, C. L., Rosa, R. P. F. \& Santorum, K. M. T. (2018). Intervindo nos processos de formação para o cuidado em saúde: uma experiência com o método de instruções ao sósia. Revista Brasileira de Saúde Ocupacional, 43(1. supl.), e9s.

Dardot, P. \& Laval, C. (2016). A nova razão do mundo. São Paulo: Boitempo.

Dejours, C. (2012). Trabalho vivo: trabalho e emancipação (Tomo II). Brasília: Paralelo 15.

Franco, T. \& Druck, G. (2008, 28-29 de novembro). O trabalho contemporâneo: precarização e saúde mental [Mesa redonda]. Seminário Nacional de Saúde Mental e Trabalho, São Paulo.

Freire, P. (1987). Pedagogia do oprimido (17 a ed.). Rio de Janeiro: Paz e Terra. (Originalmente publicado em 1970)

Garcia, P. B. (1980). Educação popular: algumas reflexões em torno da questão do saber. In A. Bezerra \& C. R. Brandão (Orgs.), A questão política da educação popular (pp. 88-121). São Paulo: Brasiliense.

Harvey, D. (1992). A condição pós-moderna. São Paulo: Loyola.

Lacaz, F. (2009). Qualidade de vida n(d)o trabalho: um conceito político e polissêmico. Trabalho, Educação e Saúde, $7(3), 565-572$.

Lhuilier, D. (2006) Cliniques du travail. Ramonville Saint-Agne: Editions ERES.

Muniz, H. P., Brito, J., Souza, K. R., Athayde, M. \& Lacomblez, M. H. (2013). Ivar Oddone e sua contribuição para o campo da saúde do trabalhador no Brasil. Revista Brasileira de Saúde Ocupacional, 38(128), 280-291.

Muniz, H. P., Santorum, K. \& França, M. B. (2018). O corpo-si: a construção do conceito na obra de Yves Schwartz. Fractal: Revista de Psicologia, 30(2), 69-77.

Neves, M. Y. R., Muniz, H. P., Alvarez, D., Fiqueiredo, M. G. \& França, M. B. (2018). A formação como estratégia de pesquisa e intervenção em saúde do trabalhador. Revista Brasileira de Saúde Ocupacional, 43(1. supl.), e8s.

Neves, M. Y. R., Muniz, H. P., Silva, E. F., Costa, J. D., Brito, J. \& Athayde, M. (2015). Saúde, gênero e trabalho nas escolas públicas: potencialidades e desafios de uma experiência com o dispositivo "Comunidade Ampliada de Pesquisa e Intervenção". Laboreal, 11(1), 53-68.

Oddone, I., Re, A. \& Briante, G. (1981). Redécouvrir l'expérience ouvrière: vers une autre psychologie du travail? Paris : Messidor.

Osorio da Silva, C. (2014). Pesquisa e Intervenção em clínica da atividade: a análise do trabalho em movimento. In P. F. Bendassolli \& L. A. P. Soboll (Orgs.), Métodos de pesquisa e intervenção em psicologia do trabalho: clínicas do trabalho (pp. 81-100). São Paulo: Atlas.

Osorio da Silva, C. \& Barros de Barros, M. (2013). Oficina de fotos: um método participativo de análise do trabalho. Universitas Psychologica, 12(4), 1325-1334.

Padilha, V. (2009). Qualidade de vida no trabalho num contexto de precarização: a panaceia delirante. Trabalho, Educação e Saúde, 7(3), 549-563.

Schwartz, Y. (2000). A comunidade científica ampliada e o regime de produção de saberes. Trabalho Eే Educação, (7), $38-46$

Schwartz, Y. (2010a). O homem, o mercado e a cidade. In Y. Schwartz \& L. Durrive (Orgs.), Trabalho e ergologia: conversas sobre a atividade humana (2a ed. pp. 247-273). Niterói: EdUFF.

Schwartz, Y. (2010b). Trabalho e ergologia. In Y. Schwartz \& L. Durrive (Orgs.), Trabalho e ergologia: conversas sobre a atividade humana (2a ed. pp. 25-46). Niterói: EdUFF.

Schwartz, Y. (2010c). Anexo ao capítulo 5: a dimensão coletiva do trabalho e as Entidades Coletivas Relativamente Pertinentes (ECRP). In Y. Schwartz \& L. Durrive (Orgs.), Trabalho e ergologia: conversas sobre a atividade humana (2 ed. pp. 149-164). Niterói: EdUFF. 
Schwartz, Y. (2014). Motivações do conceito de corpo-si: corpo-si, atividade, experiência. Letras de Hoje, $49(3), 259-274$.

Schwartz, Y. (2015). L'activité peut-elle être objet d' "analyse”?. Letras de Hoje, 50(supl.), s42-s52.

Schwartz, Y. (2016). Diálogo 2 - debates de normas, "mundo de valores" e engajamento transformador. In Y. Schwartz \& L. Durrive (Orgs.), Trabalho e Ergologia II: diálogos sobre a atividade humana (pp. 55-149). Belo Horizonte: Fabrefactum.

Schwartz, Y. \& Durrive, L. (2016). Esquema geral do dispositivo a três polos. In Y. Schwartz \& L. Durrive (Orgs.), Trabalho e Ergologia II: diálogos sobre a atividade humana (pp. 387-388). Belo Horizonte: Fabrefactum.

Simonet, P. \& Poussin, N. (2014). La socialisation des gestes de métier : un enjeu de santé au travail qui interroge la formation. Éducation Permanente, (HS6), 121-135.

\section{Endereços para correspondência}

heldermuniz@uol.com.br

Recebido em: 25/10/2019

emoraesteixeira@gmail.com

Revisado em: 09/08/2020

claudia.osorio.uff@gmail.com

Aprovado em: 11/08/2020 